\title{
Dominación, apropiación y accesibilidad en la producción territorial del Alto Sinú desde la construcción de la hidroeléctrica de Urrá, 1994-2019
}

DOMINION OVER, APPROPRIATION OF, AND ACCESSIBILITY TO TERRITORIAL PRODUCTION IN ALTO SINÚ SINCE THE CONSTRUCTION OF THE URRÁ HYDROELECTRIC POWER PLANT, 1994-2019

\author{
DOMINAÇÃO, APROPRIAÇÃO E ACESSIBILIDADE NA PRODUÇÃO \\ TERRITORIAL DO ALTO SINÚ DESDE A CONSTRUÇÃO DA HIDRELÉTRICA
}

DE URRÁ, 1994-2019

Patricia Gómez Zárate ${ }^{1}$ Sergio Iván Arroyave Arrubla ${ }^{2}$

Para citar este artículo: Gómez Zárate, P., \& Arroyave Arrubla, S. (2020). Dominación, apropiación y accesibilidad en la producción territorial del Alto Sinú desde la construcción de la hidroeléctrica de Urrá, 1994-2019. Perspectiva Geográfica, 25(1), 35-55. https://doi.org/10.19053/01233769.9316.
Recepción:

22 de abril de 2019

Evaluación:

17 de marzo de 2020

Aprobación:

28 de abril de 2020

\section{Resumen}

Este artículo presenta un análisis desde la geografía crítica sobre la producción del territorio del Alto Sinú entre 1994 y 2019 en relación directa con la construcción de la hidroeléctrica de Urrá, a partir de la identificación del proceso de planeación y construcción de la hidroeléctrica, de las transformaciones territoriales vividas por las poblaciones locales, campesinos y embera-katíos, y de la presencia del conflicto armado, a través de una investigación etnográfica con énfasis en el análisis territorial.

\footnotetext{
Maestra en Geografía Humana de El Colegio de Michoacán, A. C., México. Estudiante de doctorado en Ciencias Sociales en El Colegio de San Luis, A. C, México. Correo electrónico: pgzarate28@gmail.com. orcid.org/0000-0002-1894-4136.

2 Maestro en Geografía Humana de El Colegio de Michoacán, A. C., México. Estudiante de doctorado en Ciencias Sociales en El Colegio de San Luis, A. C, México. Correo electrónico: arrurrubla@gmail.com. orcid.org/0000-0002-7124-6070.
} 
Encontramos que la producción del territorio actual del Alto Sinú se da a partir de la interacción de tres dimensiones de la práctica territorial: dominio, apropiación y accesibilidad, en donde el dominio se concreta por medio de medidas de control como acciones legales y extralegales, la apropiación se refleja en patrones de asentamiento y organización socioeconómica, y la accesibilidad da cuenta de restricciones a ciertos servicios importantes como la energía eléctrica.

Palabras clave: territorio, Alto Sinú, hidroeléctrica, práctica territorial, energía, geografía crítica.

\section{Abstract}

This article presents an analysis from critical geography on territorial production in Alto Sinú between 1994 and 2019 regarding the construction of the Urrá hydroelectric power plant. Through ethnographic research focused on territorial analysis, it identifies the planning and construction process of the hydroelectric power plant, the territorial transformations experienced by local populations, peasants, and Embera-Katíos, and the ongoing armed conflict. It was found that production in Alto Sinú derives from the interaction of three dimensions of territorial practice: dominion, appropriation, and accessibility. Dominion materializes in control measures such as legal and non-legal actions; appropriation reflects in settlement and socioeconomic organization patterns; and accessibility accounts for restrictions on certain important services such as electrical power.

Keywords: Territory, Alto Sinú, hydroelectric power plant, territorial practice, energy, critical geography.

\section{Resumo}

Este artigo apresenta uma análise a partir da geografia crítica sobre a produção do território do Alto Sinú entre 1994 e 2019 em relação direta à construção da hidrelétrica de Urrá, com base na identificação do processo de planejamento e construção da hidrelétrica, das transformações territoriais vividas por populações locais, camponeses e a tribo Emberá-Katíos, e da presença do conflito armado, através de uma pesquisa etnográfica com ênfase numa análise territorial. Nós achamos que a produção do atual território do Alto Sinú ocorre a partir da interação de três dimensões da prática territorial: domínio, apropriação e acessibilidade, onde é concretizado o dominio por meio de medidas de controle, como ações legais e extralegais, a apropriação se reflete nos padrões de assentamento e organização socioeconômica, e a acessibilidade é responsável por restrições a certos serviços importantes, como a energia elétrica.

Palavras-chave: território, Alto Sinú, hidrelétrica, prática territorial, energia, geografia crítica. 


\section{Introducción}

Los estudios sobre los diferentes conflictos ocasionados por la instauración de la hidroeléctrica de Urrá I en el Alto Sinú, departamento de Córdoba, se han enfocado en dos vertientes que algunas veces son complementarias. Una privilegia la dimensión ambiental destacando las afectaciones ecosistémicas desde un punto de vista ecológico, en la que prima una visión biológica (Bustamante, 2008; Neira \& Neusa; 2016). La segunda perspectiva puede ser considerada dentro de la ecología política, en la cual se reivindican los movimientos sociales indígenas y se destacan los daños infligidos por parte de la Empresa Urrá E.S.P. S.A. a los modos de vida indígena y a sus fuentes de sustento basadas en el territorio (Caviedes, 2004; Rodríguez \& Orduz, 2012; Castrillón, Jaramillo \& Mesa, 2008).

Si bien estas dos vertientes han dado grandes aportes al entendimiento y la visibilización de conflictos en el Alto Sinú, han dejado por fuera de sus análisis el papel y las afectaciones de los campe$\operatorname{sinos}^{3}$ que también habitan allí, es decir, ninguna de estas perspectivas efectúa un análisis territorial que tenga en cuenta las transformaciones e interacciones de los principales actores involucrados: los embera-katío, los campesinos y la Empresa Urrá E.S.P. S.A.

Este artículo tiene como finalidad dar cuenta de la producción del territorio del Alto Sinú a partir de la construcción de la hidroeléctrica de Urrá I entre 1994 y 2019 desde la perspectiva de la geo-

El campesino en Colombia se ha definido por la pertenencia a una sociedad mayor con la que posee dinámicas de dependencia y autonomía, en las que se destacan las condiciones de trabajo, la tenencia de la tierra y el modo de vida rural, las cuales hacen que un individuo o grupo sean catalogados como campesinos (Wolf, 1978; Fajardo, 2014). grafía crítica, con la intención de reflexionar sobre la complejidad de la creación de procesos territoriales en contextos rurales colombianos. Por tanto, consideramos que la resignificación de un territorio rural, de explotación de madera y agricultura de subsistencia con generación de pocos excedentes a uno de producción hidroenergética trajo consigo fuertes transformaciones en la organización social del territorio de los diferentes actores que lo conforman (Figura 1).

Las geografías críticas o radicales tienen como base el pensamiento de Marx y se sustentan ontológicamente en el materialismo. Tienen como fundamento realizar una crítica al sistema de la sociedad occidental, con el objetivo de aportar a una nueva configuración espacial de la vida en el mundo (Mattson, 1978; Ortega, 2000), y toma como base la idea de totalidad, es decir, el estudio de la interrelación, en conjunto, entre los principales procesos y actores multiescalares de configuración y dinamismo de los territorios (Osorio, 2016).

Nosotros entendemos el territorio como la vinculación de la dimensión espacial con las relaciones humanas, donde priman las relaciones de poder; además lo asumimos como el espacio en el que se ha proyectado trabajo, transformación de energía e información (Raffestin, 2013) ${ }^{4}$. Por tanto, el territorio comprende diferentes tipos de apropiación o dominación de un espacio desde grupos humanos, que es múltiple y multiescalar (Haesbaert, 2011),

\footnotetext{
4 Cabe aclarar que, para el análisis de tal vínculo, hay dos formas de nombrarlo: por un lado, están los autores que lo denominan espacio (Lefebvre, 2013; Santos, 2000; Harvey, 1990) y, por otro, los que lo denominan territorio (Raffestin, 2013; Mançano, 2009; Haesbaert, 2011). Si bien cada uno de ellos argumenta las diferencias teóricas entre ambos términos, estos dos conceptos son muy parecidos. Haesbaert, en la presentación de Pelo espaço de Doreen Massey (2008), afirma que el término espacio para los autores ingleses es similar al de territorio utilizado por investigadores latinoamericanos (Haesbaert, 2008).
} 


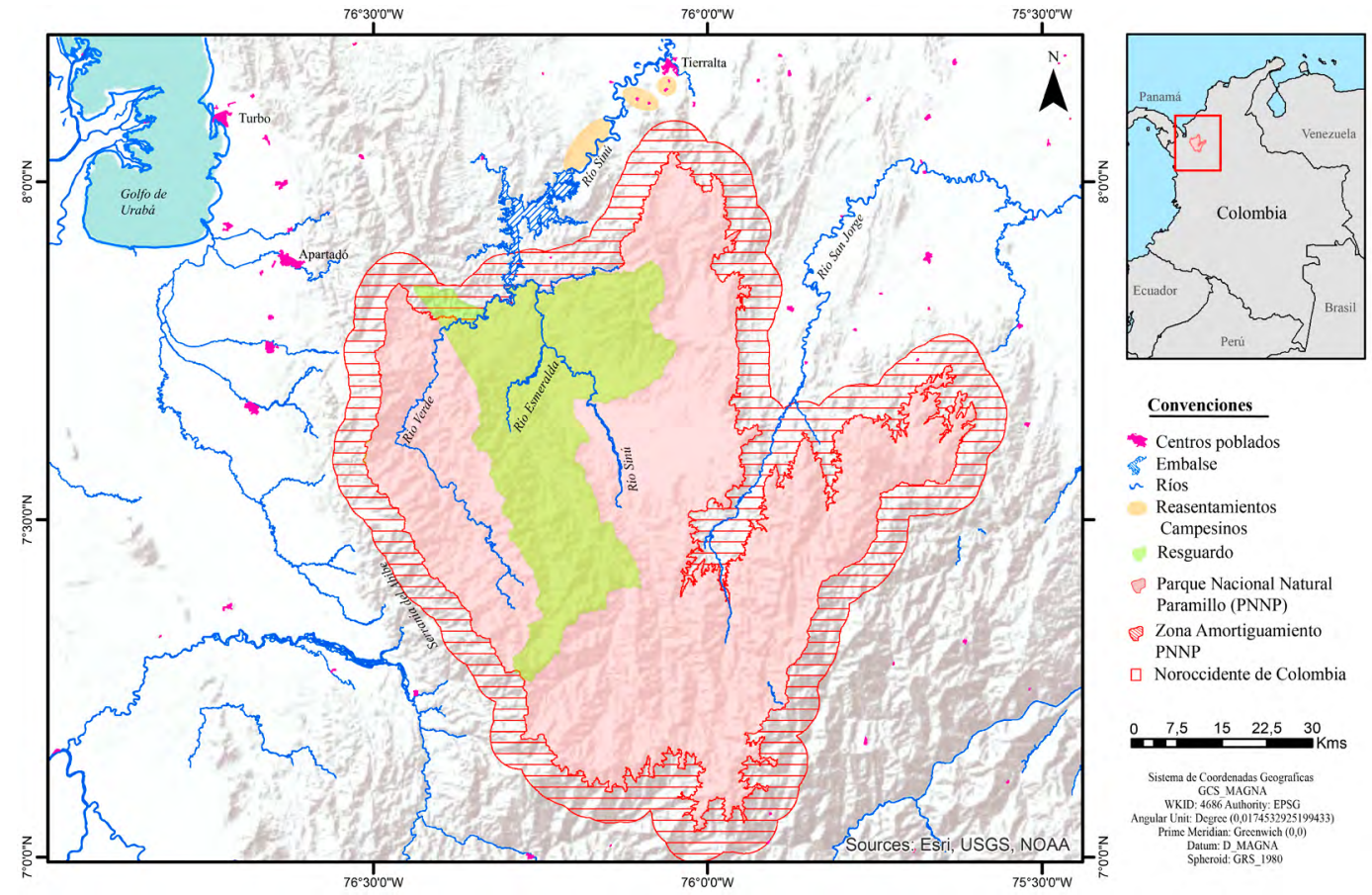

Figura 1. Ubicación de la zona de estudio

Fuente: elaboración propia con base en datos del Instituto Geográfico Agustín Codazzi (IGAC), Parque Nacional Natural (PNN) Paramillo y National Geographic Basemap - Esri (2019).

producto de la interacción de actores locales que se vinculan de diferentes maneras a procesos nacionales (Tocancipá \& Ramírez, 2018).

Las prácticas como acción social son el sustento de las concepciones objetivas de tiempo y espacio que se encuentran en los procesos materiales de reproducción y generación de la vida social. Es por esto que desarrollaremos la producción del territorio desde tres dimensiones de análisis de la práctica espacial, con base en Harvey (1998): fricción por distancia, apropiación espacial y dominio del espacio. El dominio del espacio remite al control de ciertos grupos sociales sobre el tipo de organización y producción del espacio. La apropiación indica cómo el espacio es ocupado por objetos, actividades, grupos sociales e individuos. La fricción por distancia se refiere a la capacidad de acceso o distanciamiento en las relaciones humanas, ya que el espacio genera fricción o resistencia que debe ser superada para la interacción social. De la interacción de tales dimensiones se produce el espacio (Lefebvre, 2013), categoría con la que nos referiremos al surgimiento de sistemas espaciales de prácticas, representaciones y concepciones como el uso de la tierra, el transporte y las comunicaciones, entre otros (Harvey, 1998, p. 247).

En términos metodológicos, esta investigación constó de un trabajo de campo durante el segun- 
do semestre de 2018 en el municipio de Tierralta, departamento de Córdoba. El enfoque etnográfico, como una concepción del conocimiento, ayudó a comprender la perspectiva de los actores (Geertz, 1988), de manera que las herramientas fueron la observación participante y las entrevistas semiestructuradas que se apoyaron en revisión documental y análisis del discurso. Para el desarrollo de estas se construyeron, de manera previa, guías de temas para obtener la información necesaria que dieron pautas de descripción de escenarios, actores y relaciones sociales, al indagar por las actividades y las actitudes de los actores con relación a los lugares. Esto con la intención de entender la vida cotidiana y darle una profundidad temporal para poder evidenciar las persistencias y los cambios en la producción del territorio (Rockwell, 2009), y así elaborar una representación interpretativa en la que "no es ni el mundo de los nativos, ni cómo es el mundo para ellos" (Guber, 2001, p. 15), sino una nueva narrativa híbrida (Hammersley \& Atkinson, 2009).

El artículo consta de un primer apartado en el que se describen las principales prácticas de producción del territorio del Alto Sinú entre 1994 y 2019. Un segundo segmento se dedica a la dominación y el control territorial en el proceso de la construcción y funcionamiento de la hidroeléctrica de Urrá. El tercero trata sobre la apropiación y los usos en el Alto Sinú, en el cual se hace énfasis en los cambios de los cultivos y en la organización social indígena y campesina. En el cuarto se realiza un análisis a partir de la accesibilidad y el distanciamiento de los actores locales desde la perspectiva territorial, y se toman como ejes para la reflexión las vías de comunicación, la generación y el consumo de energía, y el conflicto armado.

\section{El territorio del Alto Sinú}

El Alto Sinú está en el sur del municipio de Tierralta del departamento de Córdoba, entre las estribaciones de la cordillera Occidental y las llanuras del río Sinú. Este lugar se caracteriza por ser una región montañosa, tiene una extensión aproximada de $4.583 \mathrm{~km}^{2}$ que hace parte de la cuenca hidrográfica del río Sinú (Alzate, 1987, p. 55), el cual nace en el cerro Tres Morros (3.960 m s. n. m.) y recorre $482 \mathrm{~km}$ hasta su desembocadura en la bahía de Cispatá en el mar Caribe (Guhl, 2017).

Los embera-katío llegan al Alto Sinú por medio de migraciones, que se dieron en dos momentos: el primero fue en los siglos XVII y XVIII a causa de la colonización española y el segundo a finales del siglo XIX y durante el siglo XX, que fue generado por el avance de la colonización campesina (C. Restrepo, entrevista, 22 de septiembre de 2018). El aspecto que propició estos dos procesos migratorios fue la organización social del pueblo indígena, que estaba adaptada a la movilización y a la dispersión, pues eran sociedades sin jefatura política centralizada, con diferencias dialectales, ecológicas y culturales (Losonczy, 2006, p. 15). Es así como la estrategia ha sido buscar lugares apartados para mantener la autonomía política y persistir culturalmente (Pardo Rojas, 1980, p. 20).

Como consecuencia de la presencia española en el territorio chocoano la respuesta embera ante el avance de las instituciones coloniales fue el cimarronismo, con el que se buscaba evitar la concentración en poblados, el trabajo forzado y el tributo español (Pardo Rojas, 1980, p. 17). Una de las diásporas de los embera en los siglos XVII y XVIII llegó al occidente de Antioquia y a la cuenca alta del río San Jorge cerca de Uré, en Córdoba, y en 
menor medida al Alto Sinú, que fue paulatinamente disputado a los indígenas cuna (Vargas, 1989, p. 21).

A finales del siglo XIX y durante el siglo XX se da el segundo proceso de migración que se realizó por medio de caminos que comunican las cabeceras del río Sinú con las del río San Jorge, al igual que con el Urabá antioqueño. Así, la migración fue hecha por recorridos a pie en sentido sur-norte desde Dabeiba, el río Atrato y Chigorodó llegando a Carepa, desde donde se ingresa a la quebrada de Saiza para llegar a través de ella al río Verde (Gómez Zárate, 2011). Es así como el proceso migratorio se dio desde el norte y el occidente de Antioquia hacia el sur de Córdoba y dentro de este último departamento desde la parte alta del río San Jorge hacia el Alto Sinú, y del Bajo al Alto Sinú. En la actualidad, el pueblo Embera-Katío se en- cuentra en la parte alta del río Sinú, principalmente en sus afluentes Esmeralda, Verde y Manso, región en donde encontraron tierras amplias, menos utilizadas.

En este periodo de tiempo también se dieron migraciones campesinas que llegaron a la zona del río Manso en el Alto Sinú. Luego en las décadas de los años cuarenta y cincuenta, a causa de la época de la Violencia, suceden procesos de migración forzosa que iniciaron el desplazamiento de familias campesinas de los municipios de Dabeiba, Peque e Ituango en Antioquia, y Montería, Lorica y otras localidades de Córdoba, que tuvieron que dejar sus viviendas en los centros poblados para ocultarse en terrenos baldíos y selváticos del Alto Sinú. Las familias se esparcieron por el territorio más fértil de las planicies aluviales de los ríos Manso, Tigre y Sinú (Figura 2).

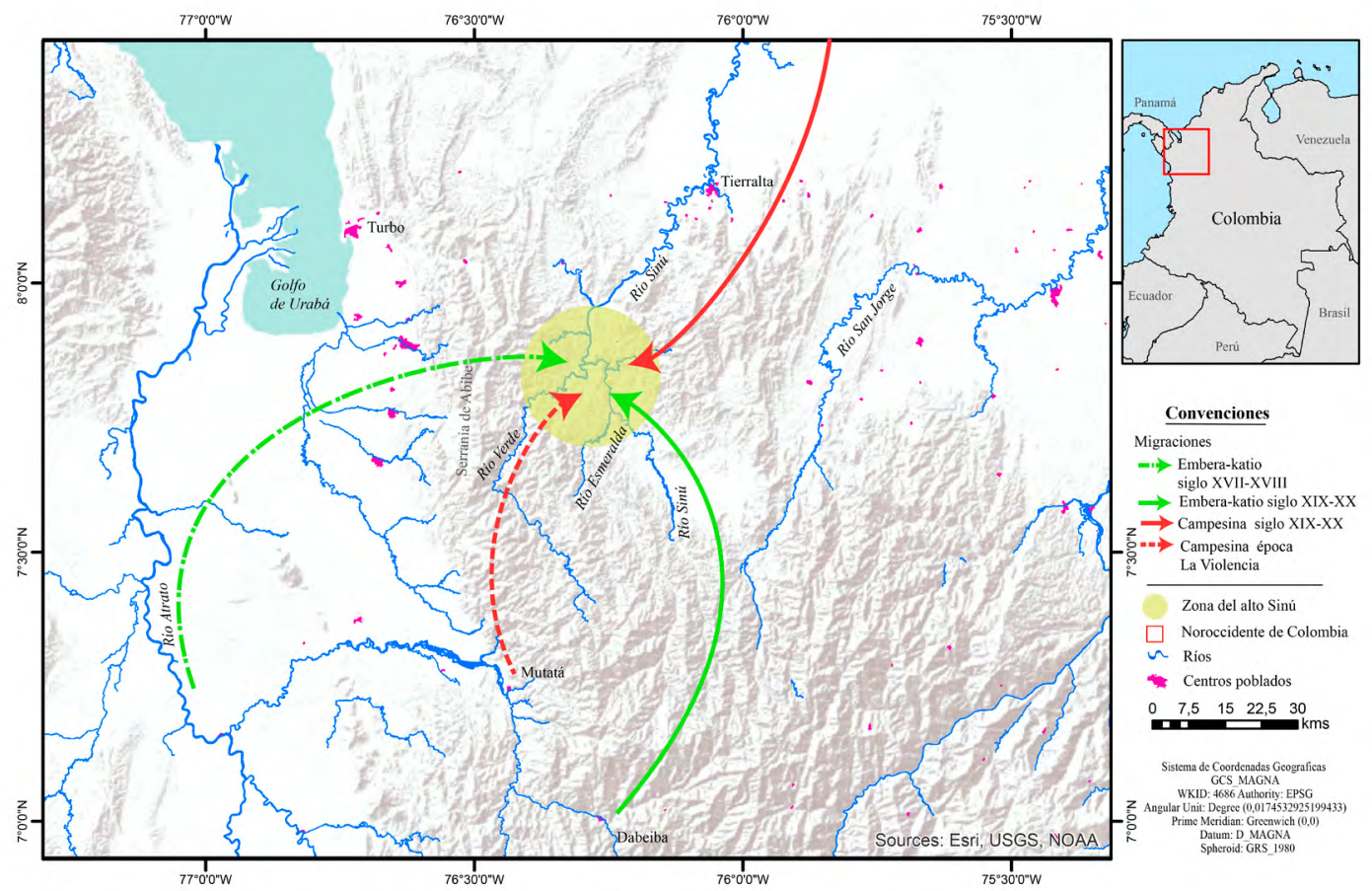

Figura 2. Migraciones de embera-katíos y campesinos entre los siglos XVIII y XX

Fuente: elaboración propia con base en datos de IGAC, Esri, United States Geological Survey (USGS) y National Oceanic and Atmospheric Administration (NOAA) (2019). 
El Estado colombiano proyectó construir las hidroeléctricas Urrá I y II a mediados del siglo XX, de acuerdo con estudios de las potencialidades del recurso hídrico (Currie, 1960). Para esto se identificó a la angostura de Urrá en el río Sinú como sitio de embalse, el cual se presentaba como límite entre la llanura y la selva pluvial, debido a que en este sitio el río se encañonaba a causa de una falla geológica, que recaudaba el 92\% de la tributación hídrica de la cuenca del río (Reichel-Dolmatoff \& Dussan, 1958, p. 34). La construcción de la hidroeléctrica inicia en la década de los noventa y en el año 2000 entra en operación comercial.

La hidroeléctrica de Urrá produce 340 MW y la Empresa Urrá S.A. E.S.P., con domicilio principal en la ciudad de Montería (Composición accionaria de la empresa Urrá S.A. E.S.P., s. f.), distribuye la energía generada entre la empresa de ferroníquel Cerromatoso $(50 \%)$ y la interconexión eléctrica nacional. La empresa es de servicios públicos mixta, del orden nacional, constituida como sociedad anónima de carácter comercial, sometida al régimen jurídico establecido en las leyes 142 de servicios públicos domiciliarios y 143 de electricidad de 1994.

En el Alto Sinú se refleja la conservación ambiental del artículo 13 de la Ley 2 de 1959, pues parte de su espacio geográfico está bajo la figura de área protegida de carácter nacional desde 1977, año en el que fue creado el Parque Nacional Natural Paramillo (Universidad de Córdoba, 1985), por lo que existe un traslape con el resguardo indígena, ya que es la otra entidad jurídica ${ }^{5}$. Su extensión aproximada es de 460.000 ha y está situado sobre el norte del departamento de Antioquia y el sur de

Resolución n 163 de 1977, por medio de la cual se delimita el PNN Paramillo, y Resolución nº53 de diciembre de 1998, que constituye el Resguardo Indígena Embera-Katío del Alto Sinú.

Vol. 25 N. ${ }^{\circ} 2$

enero - junio de 2020

pp. $35-55$
Córdoba, al norte de la cordillera Occidental, sobre el nudo del Paramillo. Su zona cubre las serranías de Abibe, San Jerónimo y Ayapel, y los municipios de Tierralta, Montelíbano y Puerto Libertador, en Córdoba, y Dabeiba, Peque e Ituango, en Antioquia. Sus ecosistemas están compuestos por páramo, selvas y bosques montañosos (Pérez Torres, Vidal Pastrana \& Racero Casarrubia, 2016).

Esta breve descripción de los actores en cuanto a orígenes, procedencias, actividades e identidades es un primer panorama del territorio actual que es producido por la interacción de las dimensiones de la práctica territorial a través del tiempo, que se complejizan a principios y mediados del siglo XX. La dominación, la apropiación y la accesibilidad serán desarrolladas en los siguientes apartados.

\section{Dominación y control territorial}

Esta dimensión de la práctica territorial está marcada por una fuerte acción de empresarios del sur del entonces departamento de Bolívar en vínculo con el Estado. Por esto se generan una serie de estrategias desde la segunda mitad del siglo XX, que se enfocan en la industrialización de la ganadería, de la explotación minera y de la producción energética. Esta última se concreta a partir de estudios sobre potencialidad hidroeléctrica, de acciones legislativas y de la construcción de la hidroeléctrica, que han implicado transformaciones en la organización social del territorio.

La unidad territorial de Córdoba surgió en 1951 al separarse del departamento de Bolívar, bajo el sustento de que la prioridad estaba centrada en Cartagena, la capital de Bolívar, y en su desarrollo turístico, dejando de lado desarrollos de tipo ganadero 
(Burgos, 1957; Exbrayat, 1994, p. 17). En los cuarenta ya se comenzaba a escuchar la propuesta de la construcción de una represa en el río Sinú. Es así como dos representantes a la Cámara presentaron un proyecto de ley para la construcción de una presa en la angostura de Urrá (Medina Rendón, 2000), una propuesta que surge de la misma bancada que promovió la separación territorial (Alzate, 1987, p. 17). El cambio en la organización del territorio inició con la proyección de un espacio concebido (Lefebvre, 2013) de mayor rentabilidad a partir de un desarrollo energético. Para esto se realizaron estudios técnicos como el elaborado en 1951 por la Misión R. J. Tipton en el río Sinú y su afluente, el río Esmeralda.

Veinte años más tarde se fortalecen las concepciones del Alto Sinú para la integración a un mercado energético, lo que se vincula a la creación de la Corporación Eléctrica de la Costa Atlántica (Corelca) ${ }^{6}$. Esta institución quedó a cargo de las proyecciones del desarrollo hidroeléctrico de Córdoba, para lo cual contrató los estudios de prefactibilidad y factibilidad en $1971 \mathrm{y}$ 1977 respectivamente. Estos estudios, en sus conclusiones, mencionan el crecimiento de la demanda de energía en la costa atlántica y la limitación para suplirla a partir de 1982; de esta manera se plantea la viabilidad de los proyectos hidroeléctricos Urrá I y Urrá II junto a otro proyecto llamado Verde I, el cual se localizaba en el río Verde, afluente del río Sinú (Consorcio Alto Sinú, 1975).

La Corporación Eléctrica de la Costa Atlántica fue creada por la Ley 59 de 1967 como un establecimiento público descentralizado, con jurisdicción en los departamentos del Atlántico, Bolívar, Córdoba, Magdalena, Sucre y Guajira, y asumió funciones y responsabilidades en lo que tenía que ver con la planeación y la ejecución de provectos de transmisión en coordinación con las electrificadoras de la costa atlántica.
Hasta ese momento, en los estudios mencionados no se reconoce la existencia ni la presencia de las comunidades locales, tanto indígenas como campesinos, como si fuera un área geográfica vacía. Sin embargo, en 1972 los embera-katío solicitaron al Estado la constitución de un resguardo en su territorio, lo cual sustentaron en evitar la penetración de colonos campesinos. En 1976 el Instituto Colombiano de la Reforma Agraria (Incora) otorga un concepto favorable para la creación del resguardo indígena, pero a pesar de esto el proceso de constitución no se dio a causa del desacuerdo entre el pueblo Embera-Katío y el Incora sobre los linderos convenientes. El Incora, en su concepto, dejó por fuera de los límites las tierras necesarias para el embalse de Urrá I. En cambio, se creó la reserva indígena de Iwagadó mediante la Resolución $n^{\circ}$ 103 del 9 de agosto de 1979, con una extensión de 9.260 ha. Cabe aclarar que la condición de reserva es una figura de tenencia de la tierra en la que el Estado sigue siendo el propietario, a diferencia del resguardo que es un título de propiedad colectiva (Incora, 1970) ${ }^{7}$.

En los años ochenta identificamos que el espacio concebido y proyectado comienza a ser planeado por medio de acciones como la determinación del carácter multipropósito del proyecto de Urrá I, que significa, además de la generación de energía, el control de inundaciones en las partes media y baja de la cuenca con el fin de favorecer la ganadería extensiva. Para esto, el Estado declaró la utilidad pública y el interés social del área necesaria para

Para los años setenta, la normatividad se sustentaba en la Ley 135 de 1961 sobre reforma social agraria, y en los noventa los territorios indígenas son regidos por la Ley 160 de 1994, por la cual se crea el Sistema Nacional de Reforma Agraria y Desarrollo Rural Campesino, y el decreto 2164 de diciembre 7 de 1995, que reglamenta la Ley 160 en lo relacionado a la dotación y titulación de tierras a las comunidades indígenas. 
la construcción de dicho proyecto mediante las resoluciones n ${ }^{\circ} 27$ del 20 de febrero de 1989 , n 142 del 18 de diciembre de 1992 y n $^{\circ} 167$ del 14 de diciembre de 1992.

Estas resoluciones significaron el paso de un territorio concebido a uno concreto, el cual había sido controlado desde un ámbito regional de la costa atlántica por Corelca; sin embargo, con la creación de la Empresa Multipropósito Urrá S.A. en 1992 el control pasa a ser departamental. El 13 de abril de 1993 el Inderena otorgó la licencia ambiental para la primera fase de la hidroeléctrica, que abarcó la construcción de las obras y la desviación del río Sinú, mediante la Resolución nº 0243/93.

Las proyecciones fueron impuestas en un territorio vivido por familias embera-katío y campesinas durante los últimos dos siglos (Figura 2), lo que implicó que las intenciones de control territorial por parte de los promotores de la hidroeléctrica tuvieran que ser negociadas con emberas y campesinos, lo cual no se tenía previsto conforme al proyecto de construcción. En este sentido, los embera-katío, con apoyo y asesoría a la Organización Nacional Indígena de Colombia (Onic) ${ }^{8}$, comenzaron a hacer visible los impactos que podría ocasionar la construcción del proyecto. Así que los embera-katío organizaron un ritual de despedida del río Sinú, para lo cual los representantes embera-katío avisaron a la entonces Empresa Multipropósito Urrá S.A. ${ }^{9}$ que se quería hacer un acto simbólico con la intención de despedir el río en vista de su próxima desviación.

Autoridad nacional de gobierno indígena que participa en reivindicaciones y resistencias en relación con la protección de territorios indígenas ancestrales desde los ochenta. Más información en https://www.onic.org.co.

En 1992 se constituyó la empresa encargada de ejecutar e provecto con el nombre Empresa Multipropósito Urrá S.A. pero en 1997 se transformó en una empresa de servicios públicos con el nombre de Empresa Urrá S.A. E.S.P.

Vol. 25 N. ${ }^{\circ} 2$

enero - junio de 2020

pp. $35-55$
De igual modo el ritual tuvo la intención de evidenciar su presencia en el Alto Sinú a nivel regional, nacional y mundial. De esta manera, el 4 de noviembre de 1994 se dio inició a la marcha fluvial indígena de 142 planchones con 665 niños, ancianos, mujeres y hombres embera-katío con el lema Do Wambura, Daibia Oyirada, "adiós río", "el que nos trae el bien", lema con el que se hacía referencia a un tipo de orden del territorio en el cual se destacaba la importancia del río como proveedor de peces y de conexión a otros mundos dentro de su cosmogonía (E. Chamarra, entrevista, 4 de diciembre de 2018).

El ritual llegó hasta Santa Cruz de Lorica, donde pronunciaron que, además de despedir al río, tenían el propósito de reclamar sus derechos como habitantes del Alto Sinú y por ende denunciar las afecciones sufridas y por venir a causa de la hidroeléctrica. Es así como exigieron una reunión con el Estado y la Empresa Multipropósito Urrá S.A., que se efectuó en Bogotá con el Ministerio del Interior, la Presidencia de la República, la Empresa Multipropósito Urrá S.A., la Defensoría del Pueblo y la Onic. Como resultado se logró firmar un acta de compromiso entre el pueblo Embera-Katío y la Empresa Multipropósito Urrá S.A. (S. Domicó, entrevista, 19 de septiembre de 2018), donde se establecieron las bases para el proceso de consulta previa ${ }^{10}$ para la licencia de la segunda etapa de la obra. Igualmente, el Incora y el Ministerio de Agricultura se comprometieron a sanear la reserva de Iwagadó comprando las mejoras a los campesinos.

\footnotetext{
10 Es un espacio de interlocución para garantizar los derechos fundamentales de integridad étnica y participación cuando se planea realizar proyectos de infraestructura o explotación de recursos naturales en territorios de régimen especial. Se estipula en la Ley 21 de 1991, la cual adopta el Convenio 169 de la Organización Internacional del Trabajo $(\mathrm{O} \mid \mathrm{T})$.
} 
De esta manera, el ritual se convierte en un hito que marca el final de un tipo de relaciones entre los embera-katío y el río, que además es un evento crucial para el movimiento social indígena y su historia, puesto que el modo en que se habían llevado a cabo las negociaciones implicó un cambio de escala en las relaciones: ya no era solo entre embera-katíos y la empresa Urrá, sino que la Onic se convirtió en intermediaria, lo que conllevó un funcionamiento del movimiento social de acuerdo con unos estándares de tipo nacional indígena, es decir, que también había una visión de organización de los territorios indígenas a escala nacional para luchar por sus derechos.

Por otro lado, los campesinos han tenido una organización social del territorio que se sustenta principalmente en procesos de colonización, es decir, donde se concibe un territorio que puede ser apropiado a partir de la labor maderera y agrícola y que generalmente es vendido a terratenientes, lo que genera más procesos de colonización y ampliación de la frontera agrícola (Molano, 1998). Sin embargo, en el Alto Sinú existen procesos de estabilización de familias campesinas que conformaron distintos poblados como Tucurá, Gallo y Frasquillo, que tenían más de cuatro décadas de existencia y fueron inundados por la represa. Entre 1995 y 1998 se da el proceso de negociación entre la empresa y los campesinos, lo que resultó en ventas de tierras y reasentamientos de los campesinos que vivían en la zona del embalse y de la cortina. Por tanto, la negociación entre la Empresa Urrá y muchos de los campesinos que ocupaban las tierras necesarias para desarrollar el proyecto hidroeléctrico no ocasionó un movimiento de resistencia colectiva, pues la venta es una de las partes del proceso de colonización (Gómez Zárate, 2018. Diario de campo).
La dominación del territorio del Alto Sinú para concretar las diferentes proyecciones de generación energética ha tenido un componente legal, que se explicó anteriormente, pero también ha tenido un componente extralegal. Los promotores de la hidroeléctrica de Urrá I han sido principalmente las élites de la región compuestas por los grandes terratenientes y ganaderos del departamento de Córdoba, quienes junto con otras elites del país han fomentado los grupos de autodefensa en la región. Generalmente, estos grupos nacen para defender los grandes intereses económicos legales e ilegales y desplazar la población de las regiones donde se tienen previstos proyectos económicos de gran rentabilidad (Romero, 2003, p. 122). Esta situación de consolidación del proyecto paramilitar en el Alto Sinú convierte a este territorio en un espacio de conflicto armado, debido a la presencia de guerrillas de izquierda como el Ejército Popular de Liberación (EPL) y las Fuerzas Armadas Revolucionarias de Colombia Ejército del Pueblo (Farc-EP) (Romero, 2003).

Los embera-katío y los campesinos no han sido ajenos al conflicto armado colombiano, pues desde la creación de las Autodefensas Campesinas de Córdoba y Urabá (ACCU), con fines de protección de los bienes económicos de hacendados y ganaderos, los pobladores se han visto expuestos a la amenaza de reclutamiento forzoso y a las inculpaciones de ser auxiliadores de grupos guerrilleros y de las autodefensas. Con el surgimiento del proyecto de la hidroeléctrica, el pueblo Embera-Katío, afectado por la falta de autonomía frente al Estado y el desconocimiento por parte del Estado como pueblo perturbado por el proyecto Urrá, opta por la resistencia civil. Esto muestra las nuevas formas de resistencia con las que los embera-katío buscan el ejercicio libre de su auto- 
nomía política en el control y la administración de sus territorios, sus recursos naturales y sus asuntos comunitarios, lo cual es un ejercicio de poder local frente a imposiciones externas. Es así como el Do Wambura, acto en el que se afirmó la decisión de permanecer en su territorio y defender la dignidad de su pueblo, los convierte en objetivo militar de las Autodefensas Unidas de Colombia (AUC) y sucedieron distintas violaciones de sus derechos que han sido denunciadas por los Cabildos Mayores (Inició asamblea indígena, 2001).

La llegada y la conformación de grupos paramilitares implicó entre los campesinos más de veinte masacres en las que fueron asesinadas más de doscientas personas entre adultos, mujeres y niños, y generaron consecuentes desplazamientos de campesinos con el fin de apoderarse de las tierras que masivamente fueron abandonadas ( $\mathrm{Ne}$ grete, 2012).

\section{Apropiación y usos}

Las dimensiones espacial y simbólica son componentes indisociables de la condición humana (Haesbaert, 2011). De esta manera la apropiación que se desarrolla en la parte alta del río Sinú implica procesos de migración, modos de vida aplicados para adaptarse al territorio e interrelaciones con los actores. Estas situaciones están en un dinamismo constante que permite cambios por medio de los procesos de interrelación. Sin embargo, la apropiación de campesinos y emberas en el Alto Sinú sufre rupturas ocasionadas por la construcción de la hidroeléctrica y el embalse, que obedecen a una apropiación y dominio sobre un territorio más amplio.

Vol. 25 N.' 2
Los cauces de agua han marcado la forma de poblamiento, debido a que el agua se establece como elemento vital para las prácticas cotidianas socioeconómicas. Comúnmente los embera se han asentado en tambos dispersos a lo largo de los ríos y quebradas, lo cual ha permitido la conformación de unidades familiares autónomas económicamente, es decir, que no se presentaban agrupaciones de viviendas como aldeas o poblados (Gordon, 1983, p. 23). El colono campesino, al llegar a tierras que consideró deshabitadas, también tuvo la posibilidad de asentarse de manera dispersa seleccionando un lugar para la casa y otro para el cultivo y la cría de animales (Gómez Zárate, 2018. Diario de campo).

Los asentamientos indígenas, después de la construcción de la hidroeléctrica, en su mayoría, cambiaron el patrón disperso y en varias comunidades los tambos se encuentran bastante cercanos el uno del otro, lo que conllevó la formación de poblados o aldeas, razón por la cual las áreas de cultivo se encuentran alejadas de los tambos. El agrupamiento en una aldea, en gran parte, se debe a las facilidades que proporciona en cuanto a organización, pues es más fácil el desplazamiento para realizar las reuniones de gobierno local, así como la construcción de escuelas y tambos de gobierno que generan una centralización territorial en cada comunidad ${ }^{11}$. En cambio, las migraciones de familias campesinas generaron desde el principio pequeños centros poblados que se formaron en relación con el comercio. Por esto se conformaron poblados en el río Manso, en Saiza, en Tucurá, en Frasquillo, en Gallo y en Cru-

Gordon (1983) menciona el asentamiento disperso a lo largo de los ríos desde que eran referenciados como chocoes; sin embargo, durante el trabajo de campo (segundo semestre de 2018) se observó que el patrón era concentrado en poblados a raíz de la hidroeléctrica, conforme a lo indagado en varias entrevistas. 
cito. Tucurá, Frasquillo y parte de Gallo fueron inundados por el embalse y sus habitantes fueron reasentados en nuevos espacios (Gómez Zárate, 2018. Diario de campo).

Los campesinos y los indígenas cultivan plátano y maíz, crían cerdos y gallinas, lo que los hace tener un sistema productivo similar. Además, en la época de los ochenta compartieron la explotación maderera, una actividad económica que tenía varias formas de relacionamiento entre emberas y campesinos: por una parte, el embera le rentaba la tierra al campesino, quien talaba y jalaba los palos por el monte hasta llegar al río y los llevaba hasta los puertos. Luego los embera aprendieron los oficios de la tala de madera y hacían todo el proceso ellos mismo. A partir de los años noventa se hace efectiva la prohibición de la tala de algunas especies de árboles que es impuesta por las entidades ambientales y ejecutada por el puesto de control del Ejército Nacional en el puerto de Frasquillo Nuevo (C. Restrepo, entrevista, 9 de septiembre de 2018).
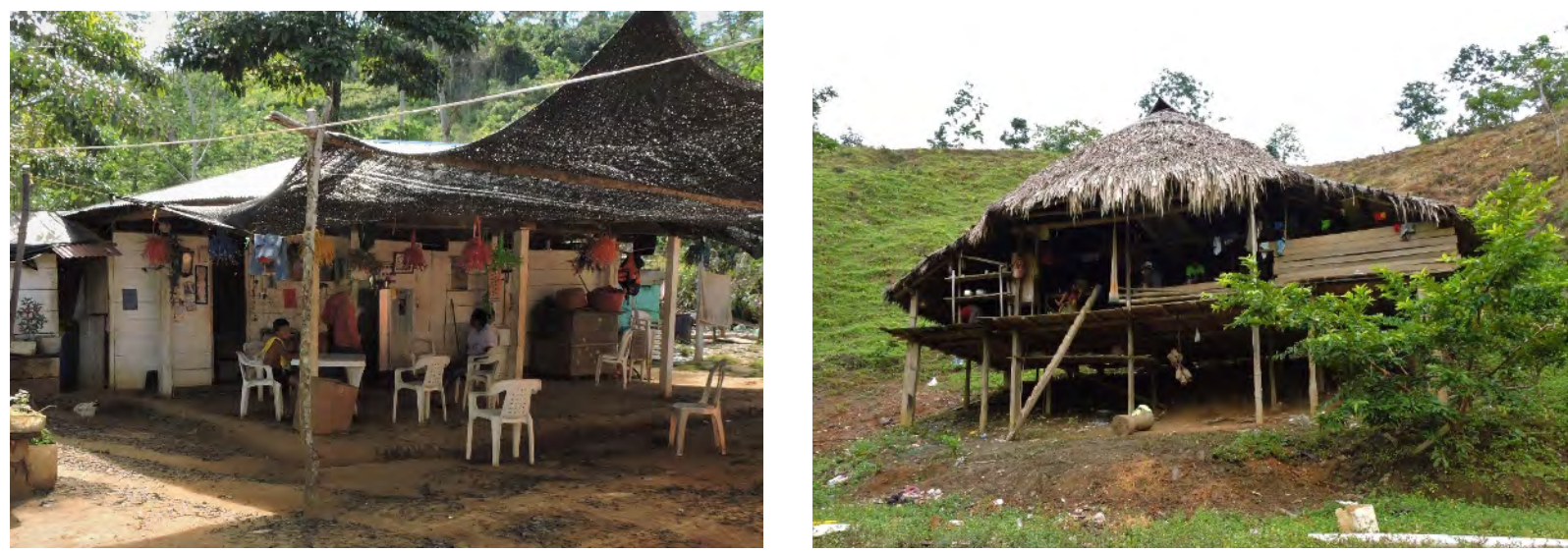

Además de las actividades económicas, la vivienda también es relevante en cuanto a la dimensión de la apropiación en las prácticas territoriales. El tambo o la vivienda embera consiste en una construcción palafítica o lacustre de planta cuadrada. Cerca de las esquinas de la planta se encuentran los cuatro horcones o pilones, que tienen hendiduras en la parte alta con el fin de servir de apoyo a un anillo redondo sobre el cual descansa el techo cónico que es cubierto con hojas de palma de iraca o bijao. Amarrados al techo cónico y extendidos hacia fuera se construyen varios anexos de techo plano, en los cuales se ubican la cocina y el área del dormitorio. El acceso al tambo se hace por medio de una escalera formada con un tronco de madera que tiene peldaños labrados (Figura 3). La casa campesina está hecha de tablas de madera y algunas veces están pintadas. Tienen de uno a tres cuartos cerrados. El piso es la tierra arenosa, tiene techo de zinc y no tiene ventanas, así que el aire se cuela por los espacios entre las lajas de madera. La puerta de cada cuarto y la cocina dan a la parte exterior de la casa, que suele ser un espacio de socialización familiar y vecinal (Figura 3).

Figura 3. Tipos de vivienda. Izquierda: tambo (vivienda) embera-katío; derecha: casa campesina aguas arriba de la hidroeléctrica

Fuente: fotografías tomadas por Patricia Gómez, septiembre de 2018. 
La represa para la generación de energía inundó 7.400 ha de tierras que eran apropiadas por los campesinos, razón por la cual la Empresa Urrá llevo a cabo un proceso de reasentamiento de 590 familias y de compra de tierras. La negociación entre empresa y campesinos se dio, por una parte, para informar los pagos que se iban a realizar a quienes tenían título de propiedad y, por otra, para acordar los tipos de casa que se proporcionarían a las familias reasentadas y el tamaño de la parcela. Las casas en las que fueron reasentadas las familias campesinas son de dos tipos: la casa uno consta de dos cuartos y un área social, el baño está fuera y no tiene cocina, y la dos tiene dos cuartos, cocina, baño y un tanque de agua; su estructura es en ladrillo y cemento, tiene techo de zinc y ventanas de metal y vidrio (R. Álvarez, entrevista, 21 de septiembre de 2018).

El proceso de reasentamiento ha significado para las familias campesinas la perdida de vínculos tanto familiares como vecinales, es decir que fueron fragmentadas las redes de colaboración que se sustentaban en las actividades socioeconómicas. Las zonas aluviales del río Sinú se caracterizaban por los cultivos de plátano, los cuales no necesitaban procesos de fertilización y la producción era constante. Las tierras de las parcelas en los reasentamientos necesitan procesos de fertilización de tipo agroindustrial y la producción de plátano se redujo a dos veces en el año (A. Pérez, entrevista, 23 de noviembre de 2018). De manera similar, los embera-katío perdieron tierras de cultivo a causa de la sedimentación generada por la inundación, $\mathrm{y}$, además, la disponibilidad de peces para la alimentación disminuyó considerablemente, lo cual ha alterado su dieta alimentaria.
Estas transformaciones e impactos sobre los embera-katío y los campesinos son una pequeña parte de los ocasionados por el proyecto hidroeléctrico. En este sentido, la empresa, en su forma de apropiación territorial, ha venido desarrollando medidas de mitigación que se enmarcan en dos formas: la indemnización dada a los indígenas y la financiación de proyectos de salud, fortalecimiento cultural, transporte y actividades productivas que son otorgados a campesinos y emberas.

En 1998 la Corte Constitucional ordenó a la Empresa Urrá por medio de la Sentencia T-652/98 indemnizar económicamente al pueblo Embera-Katío por las afectaciones causadas por el desarrollo del proyecto hidroeléctrico Urrá I. Los pagos de la indemnización comenzaron a hacerse efectivos a partir de marzo de 2006 y desde este momento cada familia embera-katío ha venido recibiendo una cantidad mensual por cada miembro familiar, incluidos los niños y las niñas. El acceso al dinero ha generado monetarización o mercantilización de la cultura embera-katío, lo cual se manifiesta en los altos costos de los servicios de jaibaná, en la presencia del dinero en las celebraciones, las cuales se utilizan para obtener beneficio monetario, y en el pago por la colaboración en el trabajo del cultivo que ha desplazado el intercambio de favores, parte fundamental del modo de vida embera. Por otra parte, esta recepción de dinero ha generado la confluencia de prestamistas y casas de empeño en Tierralta, que han facilitado a los embera la compra de electrodomésticos por medio de créditos usureros (Gómez Zárate, 2011).

La Onic y la primera organización de representación, los Cabildos Mayores de río Sinú y río Esmeralda de los embera-katío, realizaron un 
diagnóstico socioeconómico de las comunidades y el diseño de un plan de mitigación, que se llamó Plan Embera Jenené, dentro del cual se desarrollaron nueve programas y en cada uno de ellos han sido llevados a cabo distintos proyectos $(\mathrm{Ca}-$ bildos Mayores Embera Katío del Alto Sinú [Camaemka], 2005). Los grupos campesinos también han recibido apoyos para el financiamiento de proyectos por medio de la conformación de asociaciones productivas de peces y plátano principalmente. La Empresa Urrá afirma que la financiación que proporciona para el desarrollo de los proyectos representa una oportunidad para el mejoramiento socioeconómico gracias al desarrollo de distintos programas que ofrecen nuevas y efectivas formas de producción.

El Parque Nacional Natural Paramillo es otro actor que apropia el territorio del Alto Sinú, el cual, como institución estatal, se rige por la normatividad nacional, y a partir de un reconocimiento de la diversidad del parque es que se encuentran planteados los objetivos del mismo, que se sustentan en la conservación ambiental para asegurar la permanencia de los distintos ecosistemas naturales presentes (Unidad Administrativa Especial del Sistema de Parques Nacionales Naturales [UAESP$\mathrm{NN}], 2005)$. En relación con los embera-katío, la gestión hace referencia a la conservación del conocimiento tradicional asociado al manejo del medio ambiente y es en este contexto que la autonomía del pueblo Embera-Katío se encuentra limitada por las consideraciones del parque, puesto que es necesario entrar en una situación de diálogo antes de realizar cualquier actividad que involucre alteraciones en el entorno. En contraste, los campesinos no tienen derecho a habitar ninguna zona declarada como área protegida, aunque se da su presencia en algunas zonas, lo cual se identifica, por parte de las autoridades del parque, como una situación de conflicto por uso, ocupación y tenencia del territorio protegido, debido a que se generan fuertes presiones sobre los valores objeto de conservación del área protegida (Pérez et al., 2016, p. 24).

En este sentido, Ulloa afirma que "declarar las zonas de mayor biodiversidad en el mundo como patrimonio universal o de la humanidad [...] implica que sus habitantes son parte de ello y tienen la responsabilidad de conservar, proteger y cuidar este patrimonio para la humanidad por encima de sus expectativas locales de desarrollo" (Ulloa, 2004, p. 301). En esta perspectiva, los indígenas son considerados como necesitados de orientación en el desarrollo y la potenciación de sus nociones de naturaleza y manejo del medio que habitan, mientras que los campesinos son considerados no dignos de habitar un área de protección ambiental. De esta manera, se reproducen discursos coloniales acerca de la necesidad de la "civilización del otro".

Por otra parte, la Empresa Urrá S.A. E.S.P. desde la perspectiva del desarrollo económico, en particular hidráulico y energético, tiene como objetivo la comercialización de la energía que produce, para lo cual es necesario el uso de última tecnología y herramientas administrativas modernas, así como criterios de eficiencia, calidad, máxima rentabilidad y sostenibilidad ambiental. La apropiación del territorio por parte de la Empresa Urrá se enfoca hacia la protección y el manejo sostenible desde la práctica de una gestión ambiental de los aspectos bióticos y abióticos presentes en el área de influencia del proyecto (Composición accionaria de la empresa Urrá S.A. E.S.P., s. f.). El discurso de la empresa muestra que su apropia- 
ción territorial, a diferencia de la de los embera y los campesinos, prioriza los lugares del embalse y la hidroeléctrica, dando así definición de zona de influencia directa e indirecta al territorio de las poblaciones locales.

\section{Accesibilidad y}

\section{distanciamiento en la interacción}

Hay unos mecanismos físicos o simbólicos que producen conexiones o impedimentos en la interacción social y que se expresan en el territorio; es esto lo que consideramos como distanciamiento o accesibilidad a recursos, productos, servicios e ideas, y es lo que llama Harvey fricción por distancia (1998). A mayor posibilidad de interacción de los actores hay mayor capacidad de resolver problemas similares de manera colectiva. Estos mecanismos van a ser descritos a partir de la comunicación, la energía eléctrica y el conflicto armado.

En la década de los setenta del siglo pasado comienzan a existir los johnson, canoas de madera con motor fuera de borda, como medio de transporte por el río Sinú que comenzó a ser usado por los campesinos, pues los embera usaban planchones de madera para bajar a Frasquillo, Tierralta o Montería, en los cuales también se regresaban. A medida que fueron aumentado los jonhson que transitaban el río, se fue normalizando esta forma de transporte para llegar a los centros comerciales; sin embargo, el uso de estos se daba preferencialmente en el sentido de subida del río. De esta manera, los excedentes de los cultivos para la venta, tanto por parte de los campesinos como de los emberas, eran transportados en planchones que se impulsaban con la corriente del río, es decir que el uso de los johnson solamente se daba para subir el río.

La represa, al alterar los flujos del río y estancarlo en cierta parte, impide la movilización de las mercancías sin costo económico, pues implicó tener que pagar por el transporte en jhonson para bajar a los puntos de venta, incrementado así los costos de producción que no eran solventados por el comprador. En la actualidad los jonhson son la única forma de transporte para ir hacia Tierralta e incluso para visitar vecinos y familias, que antes eran accesibles por medio de caminos.

En los setenta el Estado dejó de tratar el tema eléctrico a nivel regional y municipal para asumirlo de manera nacional, lo que se identifica con la creación de la Comisión Nacional de Recursos Energéticos y del Ministerio de Minas y Energía (Sandoval, 2004, p. 6). Bajo este sustento es que la hidroeléctrica, como parte de la red nacional, fue señalada como necesaria para el país, pues se justificó como un bien nacional que estaba por encima de los perjuicios a nivel local (Sandoval, 2004). Adicionalmente, otro importante cambio económico fue la división de las tareas del ciclo de la energía eléctrica y sus privatizaciones con capitales extranjeros. Se seccionó la producción de energía de la interconexión y de la venta final en hogares e industrias. Urrá se encargaría únicamente de la producción y no tendría ninguna incidencia en temas de interconexión o tarifas domiciliarias. De este modo, las expectativas locales que suponían el acceso a energía eléctrica barata para impulsar la industria local debieron ser abandonadas. Las tarifas energéticas corresponden desde entonces, en todo el país, al comportamiento de las acciones de la bolsa de valores (V. Negrete, entrevista, 26 de octubre de 2018). 
El municipio de Tierralta, para el 2014, reporta que tiene un cubrimiento de energía eléctrica menor al 50\% (Defensoría del Pueblo, 2017). El territorio habitado por emberas y campesinos aguas arriba del embalse no tiene energía, y las familias campesinas reasentadas en centros poblados por la Empresa Urrá tienen servicio de energía que es proporcionado por la hidroeléctrica, pero no es constante debido a la falta de mantenimiento de las redes, que está a cargo de la administración municipal.

La energía eléctrica, en la actualidad, se ha transformado en un servicio que condiciona la posibilidad y las formas de las interacciones, pues hay otros servicios que están relacionados con esta, como la telefonía móvil, el internet y la televisión, por tanto, no tener "la luz" implica distanciamientos y restricciones en la comunicación de las poblaciones de estos territorios. Esta necesidad de energía eléctrica es evidente en la compra de plantas eléctricas de diésel y gasolina por parte de las familias campesinas y emberas o en los constantes comentarios que hacen al respecto de dicha problemática, donde expresan su inconformidad por no tener el servicio y a la vez lo que esto representa socialmente para ellos, pues lo consideran una "forma de aislamiento, de estar lejos", que refleja en su discurso las diferencias en el distanciamiento territorial (Gómez Zárate, 2018. Diario de campo).

El proceso de producción de energía, como se ha planteado anteriormente, se ha sustentado en la idea del desarrollo del departamento de Córdoba y del país, el cual está estrechamente relacionado con el bienestar de la población. Este desarrollo, si bien ha sido un gran logro de empresarios y del Es- tado, se ha limitado a un sentido económico, como lo muestran la generación de riqueza en la Empresa Urrá y las indemnizaciones que el propio Estado ha declarado justas por los impactos ocasionados a las comunidades locales; sin embargo, los habitantes también esperan que el bienestar esté dado por tener el servicio de energía.

En el conflicto armado, la visión que ha tenido el Estado sobre los campesinos de esta zona del Alto Sinú es que potencialmente poseen una mayor vinculación con grupos ilegales, lo que los hace susceptibles a estrategias de guerra que implican la restricción de movilidad de bienes inmuebles y alimento, con el argumento de ser transferidos o comercializados a dichos grupos ilegales. Esto genera un distanciamiento simbólico o marginación entre los grupos campesinos, que no pueden llevar productos y desplazarse libremente, con respecto a los emberas, que se considera que no hacen parte del conflicto, dentro del imaginario del Estado llevado a cabo por el Ejército Nacional, que vigilaba las mercancías que subían los campesinos en el puerto Frasquillo, debido a que no debía pasar el aproximado de 100.000 pesos por grupo familiar al mes; esto, además, iba en detrimento de colaboraciones familiares y vecinales en función de "hacer el favor de llevarle cosas al compañero" (A. Torres, entrevista, 7 de noviembre de 2018).

\section{Conclusiones}

La producción del territorio como interacción de las tres dimensiones de la práctica territorial: dominio, apropiación y accesibilidad, que hemos trabajado en este artículo, permiten plantear un modelo temporal de tres periodos de interacciones en 
los que se ha configurado el territorio del Alto Sinú desde mediados del siglo XX hasta el año 2019 en función de la construcción de la hidroeléctrica.

Entre los años cincuenta y setenta del siglo pasado se dio un primer periodo en el que el Alto Sinú, a partir de un dominio estatal del territorio, se comenzó a proyectar como zona con alto potencial para la producción de hidroenergía mediante diversos estudios técnicos. Fue una etapa en la que se generó un imaginario a partir de los diversos documentos producidos, que fueron la base para el desarrollo en las siguientes décadas de la explotación hidroenergética. Otro de los dominios del territorio fue la organización social de los emberas, por familias nucleares a lo largo de los ríos, y de los campesinos, quienes vivían dispersos alrededor de un poblado comercial. La apropiación del espacio se dio por parte de campesinos y emberas desde sus modos de vida vinculados a la agricultura, lo cual ha dado lugar a traslapes territoriales. La accesibilidad a los mercados y el contacto con grupos sociales de la región se daba a partir de los ritmos naturales del río, que implicaba flujos de productos y comunicación de forma personal.

Para los años setenta, el dominio imaginado se materializa a partir de las propuestas de varios proyectos como Río Verde, Urra I y II. Fue un periodo de mayores estudios técnicos y gestiones políticas ante el Estado para que este estableciera las disposiciones legales para su realización. Es también un periodo donde se declara gran parte del Alto Sinú como área protegida para la conservación ambiental, lo cual evidencia otra faceta del dominio estatal; sin embargo, la zona necesaria para la explotación energética quedó excluida. La apropiación y la accesibilidad se expresan de la misma manera que en el periodo anterior por parte de campesinos y emberas.

En el último periodo identificado, entre los años ochenta y el presente, el dominio se caracterizó por ajustes al proyecto y solamente se construyó el proyecto multipropósito Urra I, lo cual materializó la apropiación de la empresa a raíz de la contención del agua para controlar avenidas y producir energía. Se dan cambios en las dinámicas de accesibilidad, tales como la pérdida de los ritmos naturales del río, que trajeron costos adicionales en los modos de transporte. De este hecho, destacamos tres fenómenos que dan cuenta de la producción territorial: reasentamientos de familias campesinas que fueron generados por la empresa Urrá, cambio del patrón de asentamiento embera por cuestiones políticas para facilitar el control territorial de su resguardo y separación espacial entre campesinos y emberas, que fue ocasionada por la asociación política de los embera con el movimiento indígena nacional representado por la Onic y por el proceso legal de lucha por su territorio basado en leyes que cobijan solo a los indígenas. A partir de estos fenómenos consideramos que el pueblo Embera-Katío ha logrado ciertas sinergias que le han permitido mayor acceso a instituciones estatales y organismos nacionales que pueden hacer visible su problemática; en cambio la población campesina tiene menor accesibilidad a estas instituciones y organismos, lo que los pone en desventaja para afrontar procesos de negociación y los ha llevado a ciertas marginaciones.

Si bien en los últimos cuarenta años han sucedido diversos cambios en el territorio, la producción de este ha estado marcada por una separación entre actores que ejercen principalmente un dominio en 
la organización territorial del Alto Sinú, que afecta y modifica las apropiaciones de los grupos que allí habitan. El actor principal que ejerce el dominio es la Empresa Urrá, que, a su vez, representa una clase política y empresarial del departamento de Córdoba. Es así como suceden resignificaciones del territorio en torno a su utilidad y se desarrollan proyecciones que buscan encontrar utilidades productivas, en términos industriales, de recursos como el agua. Estas proyecciones se concretan en la generación de energía y, por medio del control territorial, ocasionan resignificaciones en los procesos de apropiación y accesibilidad de los embera y los campesinos, particularmente en la obligación de cambiar los lugares de sus acciones. 


\section{Referencias}

Alzate, A. (1987). Impactos sociales del proyecto hidroeléctrico de Urrá. Montería: Fundación del Caribe.

Burgos, R. (1957). Creación y organización de Córdoba . Montería: Editorial Obregón.

Bustamante, C. (2008). Efectos ambientales generados por la construcción y operación de un embalse. (Tesis de pregrado en Ingeniería Civil). Universidad de Sucre, Sincelejo.

Cabildos Mayores Embera Katío del Alto Sinú (Camaemka). (2005). Programa de Ordenamiento del Territorio Indígena. Cabildos Mayores de río Sinú y río Verde.

Castrillón, F., Jaramillo, E., \& Mesa, G. (2008). La represa de Urrá y los embera katío del Alto Sinú: una historia de farsas y crímenes. Revista Semillas, 36-37.

Caviedes, M. (2004). Antropología apócrifa y movimiento indígena: desde los cuarenta hasta el apoyo a los embera katío. (Tesis de maestría en Antropología). Bogotá, Universidad Nacional de Colombia.

Composición accionaria de la empresa Urrá S.A. E.S.P. (S. f.). Recuperado de https://urra.com.co/composicion-accionaria/.

Consorcio Alto Sinú. (1975). Análisis técnico de las posibilidades de desarrollo hidroeléctrico del Alto Sinú, Vol-III Informe intermedio: aspectos técnicos y conclusiones Urra I, Urra II, Verde I. Bogotá: Fondo Financiero de Proyectos de Desarrollo (Fonade).

Currie, L. (1960). Programa de desarrollo económico del valle del Magdalena y norte de Colombia. Bogotá: Ministerio de Obras Públicas, Ferrocarriles Nacionales, Empresa Colombiana de Petroleos.

Defensoría del Pueblo, Colombia. (2017). Impactos socioambientales y posible afectación de derechos derivada de la generación hidroeléctrica en Colombia. Bogotá: Delegada para los Derechos Colectivos y del Ambiente.

Exbrayat, J. (1994). Historia de Montería. Montería: Alcaldía de Montería.

Fajardo, D. (2014). Las guerras de la agricultura colombiana: 1980-2010. Bogotá: Instituto Latinoamericano para una Sociedad y un Derecho Alternativos (ILSA).

Geertz, C. (1988). Interpretación de las culturas. Barcelona: Gedisa.

Gómez Zárate, P. (2011). Territorialidad y paisaje. Transformaciones socio-culturales en el pueblo Embera-Katío del Resguardo del Alto Sinú por la construcción de la Hidroeléctrica Urrá I. (Tesis de pregrado en Antropología). Bogotá, Universidad Externado de Colombia.

Gordon, B. L. (1983). El Sinú: geografía humana y ecología. Bogotá: Carlos Valencia Editores.

Guber, R. (2001). La etnografía: método, campo y reflexividad. Colombia: Grupo Editorial Norma. 
Guhl, E. (2017). Colombia. Bosquejo de su geografía tropical, vol. I (2a ed.). Bogotá: Ediciones Uniandes, Universidad de los Andes.

Haesbaert, R. (2008). Presentación. En: D. Massey, Pelo Espaço. Uma Nova política da espacialidade (pp. 9-13). Río de Janeiro: Editora Bertrand Brasil Ltda.

Haesbaert, R. (2011). El mito de la desterritorialización. Del "fin de los territorios" a la multiterritorialidad. México D. F.: Siglo XXI.

Hammersley, M., y Atkinson, P. (2009). Etnografía. Métodos de investigación. Barcelona: Paidós.

Harvey, D. (1990). Los límites del capitalismo y la teoría marxista. México: Fondo de Cultura Económica.

Harvey, D. (1998). La condición de la posmodernidad. Investigación sobre los orígenes del cambio cultural. Buenos Aires: Amorrortu.

Inició asamblea indígena. (25 de enero de 2001). El Meridiano de Córdoba, p. 4.

Instituto Colombiano de la Reforma Agraria (Incora). (1970). Compilación de normas sobre adjudicaciones, baldios, reservas indígenas, parcelaciones. Bogotá: Publicaciones del Incora.

Lefebvre, H. (2013). La producción del espacio. España: Capitán Swing.

Losonczy, A.-M. (2006). Viaje y violencia. La paradoja chamánica emberá. Bogotá: Universidad Externado de Colombia.

Mançano, B. (2009). Territorio, teoría y política. En: F. Lozano Velásquez y J. Ferro (eds.), Las configuraciones de los territorios rurales en el siglo XXI (pp. 21-51). Bogotá: Pontificia Universidad Javeriana.

Mattson, K. (1978). Una introducción a la geografía radical. Geo-crítica, 13, 1-23.

Medina Rendón, J. (15 de febrero de 2000). Urrá: una abeja que se volvió hidroeléctrica. El Tiempo. Recuperado de https://www.eltiempo.com/archivo/ documento/MAM-1269406.

Molano, A. (1988). Violencia y colonización. Revista Foro, 6, 25-37.

Negrete, V. (2012). El sur de Córdoba a la espera del plan que acabe con el conflicto, la pobreza y el deterioro ambiental. Corporación Viva la Ciudadanía. Recuperado de http://viva.org.co/cajavirtual/svc0303/pdfs/articulo244_303.pdf.

Neira, K. \& Neusa, K. (2016). Formulación de medidas de compensación por afectación de ecosistemas generada por la central hidroeléctrica Urrá l en el Parque Nacional Natural Paramillo (PNNP) - departamento de Córdoba. (Tesis de pregrado en Ingeniería Ambiental). Universidad Distrital Francisco José de Caldas, Bogotá.

Ortega, J. (2000). Los horizontes de la geografía: teoría de la geografía. Barcelona: Ariel.

Osorio, J. (2016). Fundamentos del análisis social. La realidad social y su conocimiento. México: Fondo de Cultura Económico.

Pardo Rojas, M. (1980). Transformaciones históricas en los indígenas Chocó. Ponencia presentada en el II Congreso de Antropología (pp. 1-29), Medellín, Colombia. 
Pérez Torres, J., Vidal Pastrana, C. \& Racero Casarrubia, J. (2016). Colombia, Biodiversidad asociada a los sectores Manso y Tigre del Parque Nacional Natural Paramillo. Parques Nacionales Naturales de Colombia.

Raffestin, C. (2013). Por una geografia del poder. Zamora: El Colegio de Michoacán.

Reichel-Dolmatoff, G. \& Dussan, A. (1958). Reconocimiento arqueológico de la hoya del río Sinú. Revista Colombiana de Antropología, VI, 31-160.

Rockwell, E. (2009). La experiencia etnográfica: historia y cultura en los procesos educativos. Buenos Aires: Paidós.

Rodríguez, C. \& Orduz, N. (2012). Adiós río. La disputa por la tierra, el agua y los derechos indígenas en torno a la represa de Urrá. Bogotá: Centro de Estudios de Derecho, Justicia y Sociedad, Dejusticia.

Romero, M. (2003). Élites regionales, polarización y paramilitares en Córdoba. En: M. Romero, Paramilitares y autodefensas 1982-2003. Bogotá: Instituto de Estudios Políticos y Relaciones Internacionales (IEPRI), Editorial Planeta.

Sandoval, A. M. (2004). Monografía del sector de electricidad y gas colombiano: condiciones actuales y retos futuros. Serie Archivos de Economía, n² 272. Bogotá: DNP.

Santos, M. (2000). La naturaleza del espacio: técnica y tiempo, razón y emoción. Barcelona: Ariel.

Tocancipá Falla, J. \& Ramírez Castrillón, C. A. (2018). Las nuevas dinámicas rurales en las zonas de reserva campesina en Colombia. Perspectiva Geográfica, 23(1), 31-52. https://doi.org/10.19053/01233769.5796.

Ulloa, A. (2004). La construcción del nativo ecológico. Complejidades, paradojas y dilemas de la relación entre los movimientos indígenas y el ambientalismo en Colombia. Bogotá: ICANH.

Unidad Administrativa Especial del Sistema de Parques Nacionales Naturales (UAESPNN), Dirección Territorial Noroccidental. (2005). Parque Nacional Natural Paramillo. Plan de Manejo 2004-2011. Tierralta. Recuperado de https://www. parquesnacionales.gov.co/portal/wp-content/uploads/2013/12/Paramillo.pdf.

Universidad de Córdoba, Centro de Investigaciones (CIUC). (1985). Estudio etnosocial de asentamientos en la zona de embalses, "Organización Socio-cultural Embera". Volumen IIC. Montería: Corporación Eléctrica de la Costa Atlántica, Proyecto Hidroeléctrico de Urrá.

Vargas, P. (1989). La Historia en las tradiciones de los emberás y de los tules. Arqueología. Revista de Estudiantes de Antropología, 3(10), 17-27.

Wolf, E. (1978). Los campesinos ( $3^{\mathrm{a}}$ ed.). Barcelona: Labor S. A. 